Brazilian Journal
of Chemical
Engineering

\title{
INFLUENCE OF GEOMETRIC DIMENSIONS ON THE PERFORMANCE OF A FILTERING HYDROCYCLONE: AN EXPERIMENTAL AND CFD STUDY
}

\author{
D. C. Oliveira, C. A. K. Almeida, L. G. M. Vieira, J. J. R. Damasceno and M. A. S. Barrozo \\ Faculdade de Engenharia Química, Universidade Federal de Uberlândia, Campus Santa Mônica, \\ Bloco 1K, Av. João Naves de Ávila 2121, CEP 38400-902, Uberlândia - MG, Brasil. \\ Phone/Fax: + (55) (34) 3239-4188, E-mail: luizgustavo@feq.ufu.br \\ E-mail: masbarrozo@ufu.br
}

(Submitted: July 24, 2008 ; Revised: February 27, 2009 ; Accepted: March 26, 2009)

\begin{abstract}
Filtering hydrocyclone is a device that was developed and patented by the Particulate System Research Group at the Federal University of Uberlandia. This equipment consists of a hydrocyclone whose conical section is replaced by a conical filtering wall. Thus, during the operation of these devices, besides the underflow and overflow streams, there is another stream of liquid, resulting from the filtrate produced in the porous cone. In the present work, the influence of some geometric variables of a filtering hydrocyclone was analyzed by an experimental and CFD study. The geometric variables analyzed were underflow orifice diameter $\left(\mathrm{D}_{\mathrm{U}}\right)$ and vortex finder length $(\ell)$. Data from a conventional hydrocyclone of the same configuration were also obtained. The results indicated that the performance of hydrocyclones is significantly influenced by the conical filtering wall. The incorporation of the filtering medium decreased the Euler numbers and increased the total efficiency of the hydrocyclones. Depending on the specific functions of the separator (as a classifier or concentrator) the best values of $\mathrm{D}_{\mathrm{U}}$ and $\ell$ were also found for the filtering hydrocyclone.

Keywords: Hydrocyclone; Filtration; Computational fluid dynamics.
\end{abstract}

\section{INTRODUCTION}

Hydrocyclones belong to an important group of equipments designed for solid-liquid or liquid-liquid separation in a centrifugal field. It is possible to adapt a hydrocyclone (family) to the accomplishment of several industrial activities depending on the geometrical relations among its main dimensions (Svarovsky, 1984). The employment of a certain family of hydrocyclones is generally restricted to an equipment need with a high classifying power (based on the size of particles collected in the underflow) or with a high concentrating capacity. The hydrocyclone versatility allows the employment of these devices in several separation processes of the industrial sectors such as textile, food, chemical, petrochemical, metallurgical, mineral, effluent treatment etc.

Due to the demand for hydrocyclones in applications where conventional hydrocyclones fail to meet process requirements, it is desirable to develop units that have similar advantages. Because of the difficulty in designing process units, the hydrocyclone has undergone many modifications to enable it to meet specific process requirements (Mainza et al., 2006).

In this context, the Particulate System Research Group at the Federal University of Uberlandia (PSRG/UFU) proposed the incorporation of a permeable cone to a hydrocyclone (Souza et al., 2000). The conical section of a conventional hydrocyclone was replaced with a conical filtering wall and the resulting device was named filtering hydrocyclone.

The operation of a filtering hydrocyclone is analogous to that of conventional separators, but in addition to the volumetric feed flow rate, underflow and overflow streams, there is another stream of fluid resulting from the filtrate produced in the porous cone (Vieira et al., 2005). A scheme of the filtering hydrocyclone is shown in Figure 1.

\footnotetext{
*To whom correspondence should be addressed
} 


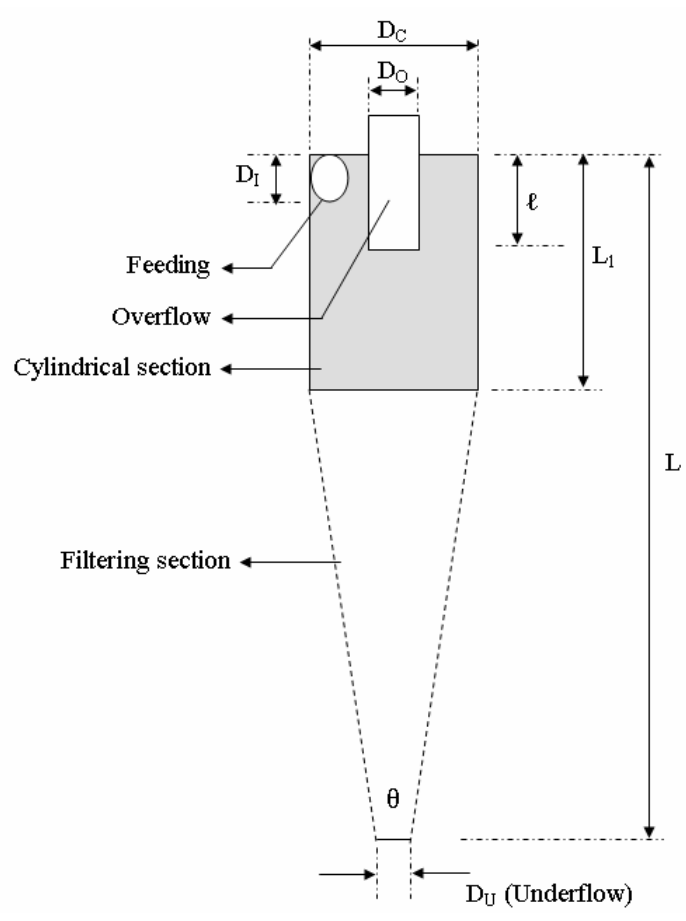

Figure 1: Scheme of the filtering hydrocyclone.

Despite the simple construction, the internal flow in filtering or conventional hydrocyclones is highly complex and of difficult mathematical calculation. The internal flow in these devices is totally turbulent and presents high vorticity preservation, vortex breakdown, flow inversion, air core etc.

This complexity of its flow processes has led designers of hydrocyclones to rely on empirical equations to predict the equipment's performance. These empirical relationships are derived from an analysis of experimental data and include the effect of operating and geometric variables (Lynch and Rao, 1975; Plitt, 1976). However, these models suffer from the same inherent deficiency as any other empirical models - the model can only be used within the extremes of the experimental data from which the model parameters were determined. In view of this shortcoming, mathematical models based on fluid mechanics are highly desirable (Vieira et al, 2007).

Recently, Computational Fluid Dynamics Techniques (CFD) have been concomitantly and alternatively used in cyclone and hydrocyclone studies (Medronho et al., 2005; Narasimha et al., 2005; Mainza et al., 2006; Bhaskar et al. 2007; Vieira et al. 2007). This technique is a versatile means to study the fluid dynamics of many physical systems and it has been widely used in engineering applications. Simulations of hydrocyclones using the incompressible Navier-Stokes equations supplemented by a suitable turbulence model have been shown to be appropriate for modelling the flow in a hydrocyclone. The use of modern CFD methods will alleviate some of the problems of using empirical models.

In a previous work, Vieira (2006) studied the influence of some geometric relationships on the performance of filtering hydrocyclones, using response surface and CFD techniques, with a view to maximizing the total efficiencies $(\eta)$ and minimizing energy costs (Eu number). However, the influence of underflow orifice diameter $\left(D_{U}\right)$ and vortex finder lengths $(\ell)$ were not studied in this previous work.

The aim of the present work is to analyze, by experimental data and CFD simulations, the influence of underflow orifice diameter $\left(D_{U}\right)$ and vortex finder lengths $(\ell)$ on the performance of the optimum configuration of the filtering hydrocyclone devised by Vieira (2006). The comparison of the performance of filtering and conventional hydrocyclone was also analyzed here.

\section{METHODOLOGY}

\section{Experimental Methodology}

The optimum configuration of the filtering hydrocyclone obtained by Vieira (2006) has been used in this study. The geometric relationships of this equipment, named $\mathrm{HF}_{11}$, are shown in Table 1 . These geometric relationships have been used in both the filtering $\left(\mathrm{HF}_{11}\right)$ and conventional $\left(\mathrm{HC}_{11}\right)$ configurations. The only difference between conventional and filtering hydrocyclones is the conical region, which consists of a porous medium in the filtering hydrocyclone. The diameter of the cylindrical section was $3 \times 10^{-2} \mathrm{~m}$.

Table 1: Geometric proportions of the hydrocyclones $\mathrm{HF}_{11}$ and $\mathrm{HC}_{11}$

\begin{tabular}{|c|c|c|c|c|}
\hline $\mathbf{D}_{\mathbf{I}} / \mathbf{D}_{\mathbf{C}}$ & $\mathbf{D}_{\mathbf{O}} / \mathbf{D}_{\mathbf{C}}$ & $\mathbf{L} / \mathbf{D}_{\mathbf{C}}$ & $\mathbf{L}_{\mathbf{1}} / \mathbf{D}_{\mathbf{C}}$ & $\boldsymbol{\theta}$ \\
\hline 0.26 & 0.22 & 6.9 & 0.5 & $11.2^{\circ}$ \\
\hline
\end{tabular}

Vieira (2006) kept fixed the dimensions of the underflow orifice diameter $(5 \mathrm{~mm})$ as well as the vortex finder length $(12 \mathrm{~mm})$. In the present work we studied the influence of underflow orifice diameter $\left(D_{\mathrm{U}}\right)$ and vortex finder lengths $(\ell)$, according to a $3^{\mathrm{k}}$ factorial design with the levels: 3,4 , and $5 \mathrm{~mm}$ for the underflow orifice diameter, and 12, 21, and 30 $\mathrm{mm}$ for the length of the vortex finder, respectivelly.

The cylinders, the impermeable cone and other accessories of hydrocyclones $\mathrm{HC}_{11}$ and $\mathrm{HF}_{11}$ were built of brass. The porous cone of hydrocyclone $\mathrm{HF}_{11}$ was built of sinterized bronze particles, whose permeability, porosity and thickness were $6.63 \times 10^{-16}$ $\mathrm{m}^{2}, \quad 0.1$ and $0.0025 \mathrm{~m}$, respectively. Each hydrocyclone was installed in a typical experimental apparatus of solid-liquid separation (Vieira 2006). 
Pressure drops of $0.9 ; 1.2 ; 1.5$ and $1.8 \mathrm{kgf} / \mathrm{cm}^{2}$ were used in the experiments.

The particulate material used in this study was phosphate rock from Fosfértil S/A - Patos de Minas (MG), whose density was $2980 \mathrm{~kg} / \mathrm{m}^{3}$. Granulometric distribution of the phosphate rock was obtained by laser diffraction, whose parameters of model RRB were: $\mathrm{D}_{63.2}=13 \mu \mathrm{m} ; \mathrm{n}=0.81$.

Suspension samples can be withdrawn at the inlet, at the underflow and at the overflow to determine the grade efficiency curve as a function of particle size. The particle size distributions of the streams were measured by laser diffractometry. The test suspension was dispersed sufficiently by a propeller stirrer to prevent sedimentation of particles at the bottom of the tank. Experiments to ascertain the separation efficiency were performed with solid concentrations at 1 vol. $\%$.

\section{CFD Simulations}

The CFD modelling approach applied to the hydrocyclone has evolved over recent years. Basically, in this approach the Reynolds Averaged Navier Stokes equations (RANS) should be supplemented by a suitable turbulence model. However, predicting the flow inside the hydrocyclone is a challenging task. The correct choice of turbulence model is a critical factor in capturing the anisotropic turbulent features of this flow, which is further complicated by the high streamline curvature. A widely used closure for the Reynolds stress is the $k-\varepsilon$ model (Dai et al., 1999; Petty and Parks, 2001; Narasimha et al., 2005). The problem with this turbulence model is that it assumes isotropic turbulence and this condition appears not to hold for the flow inside a hydrocyclone. The RSM (Reynolds Stress Model) turbulence model (Fluent, 2008; Vieira, 2006) deals with the effects of streamline curvature, swirl, and rapid changes in the strain rate in a more rigorous manner than the classical $k-\varepsilon$ model does. Therefore, this model (RSM) has a greater potential to accurately predict complex flows, as in the case of hydrocyclones (Schuetz et al., 2004; Cullivan et al. 2004; Medronho et al., 2005; Bhaskar et al. 2007; Vieira et al. 2007). A detailed discussion of the numerical method is given by Fluent (2008).

In the present work, the CFD simulations have been used to analyze the influence of underflow orifice diameter $\left(D_{U}\right)$ and vortex finder lengths $(\ell)$ on the behavior of the filtering hydrocyclone. The same simulation strategy adopted in our previous paper (Vieira et al., 2007) has been used here. So, the simulations were performed using the computational fluid dynamics package Fluent, using a twodimensional double precision, steady-state segregated solver. The numerical solution of the equations was based on the Finite Volume method. The Reynolds Stress Model (RSM) was implemented to provide turbulence closure. PRESTO (Pressure staggered option) and SIMPLE (Semi-Implicit Pressure Linked Equations) schemes were employed for pressure discretization and pressure-velocity coupling, respectively. For the discretization of all other conservation equations a Second Order Upwind algorithm, based on TVD upwind family of schemes (Fluent, 2008), was used. A Cartesian coordinate system was used, with approximately 100000 rectangular meshes applied to the hydrocyclones. Pressure outlet boundary condition types were specified at the hydrocyclone discharge orifices, at which a standard atmospheric pressure condition was prescribed. The values of the inlet velocities were established according to operating conditions.

In the present study, we have worked with dilute suspensions. In this case, it could be assumed that the particles interact mostly with the fluid without significantly changing the fluid transport properties. In our previous work (Vieira, 2006), a Lagrangian approach, where the paths of individual particles are tracked based on the velocity predicted by a previous CFD simulation of the fluid, have been performed and the results showed good agreement with the experimental data.

\section{RESULTS AND DISCUSSION}

This section is divided into two parts. Firstly, the influence of the presence of the conical filtering wall is discussed. In the second section, the influence exerted by variables $\mathrm{D}_{U}$ and $\ell$ on the performance of the filtering hydrocyclone is analyzed. In both sections, experimental data and CFD simulations are used for a better understanding. The filtering and conventional hydrocyclones are dubbed $\mathrm{HF}_{11}$ and $\mathrm{HC}_{11}$, respectively

\section{Influence of the Presence of Conical Filtering Wall}

Figure 2 presents results from the experimental data for the Euler Number (ratio of pressure and inertial forces) of hydrocyclones $\mathrm{HF}_{11}$ and $\mathrm{HC}_{11}$ as a function of pressure drop. In this figure lower Euler numbers can be observed for the filtering hydrocyclone $\left(\mathrm{HF}_{11}\right)$ than for the conventional one $\left(\mathrm{HC}_{11}\right)$.

In the same way, Figure 3 shows CFD results with the comparison between total pressure profile (relative to an atmospheric pressure value) of hydrocyclones $\mathrm{HC}_{11}$ and $\mathrm{HF}_{11}$ of the same geometry $\left(D_{U}=5 \mathrm{~mm}, \ell=21 \mathrm{~mm}\right)$ and with the same inlet flowrate $\left(\mathrm{Q}=301 \mathrm{~cm}^{3} / \mathrm{s}\right)$. The pressure drop in the filtering hydrocyclone $\left(\mathrm{HF}_{11}\right)$ was smaller because 
the porous cone represented an additional exit of liquid into the filtering equipment. In this device $\left(\mathrm{HF}_{11}\right)$, besides the underflow and overflow exit streams, there is an additional stream of fluid resulting from the filtrate produced in the porous cone. So, these simulated results also indicate lower Euler numbers for the filtering hydrocyclone, i.e., lower energetic costs.

The incorporation of filtering cone also favored the solid-liquid separation in hydrocyclones. Figure 4 shows the experimental results of the cut size (d50) for the filtering and conventional hydrocyclones with the same geometry (DU $=4 \mathrm{~mm} \mathrm{e} \ell=12 \mathrm{~mm}$ ). It can be seen in this figure that, in the same operational condition, the filtering device (HF11) presented lower cut size (d50) than the conventional one (HC11). Thus, under the same conditions, the filtering hydrocyclone (HF11) has greater total efficiency.

CFD Simulations are a useful tool for understanding

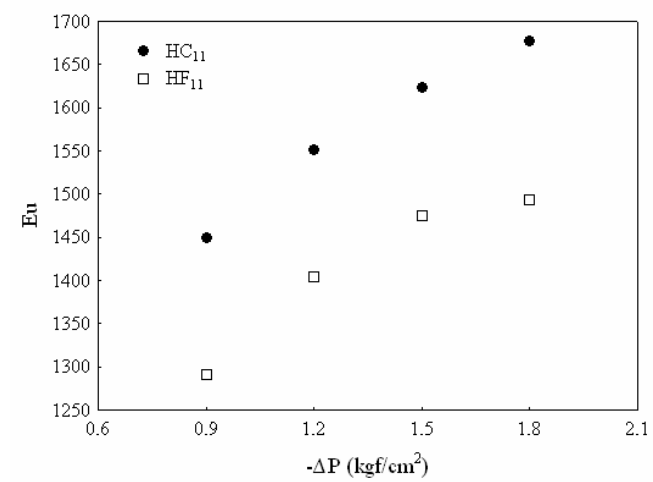

Figure 2: Experimental results of Euler Number (Eu) for the filtering and conventional hydrocyclones (DU $=5 \mathrm{~mm}$ and $\ell=21 \mathrm{~mm}$ ).

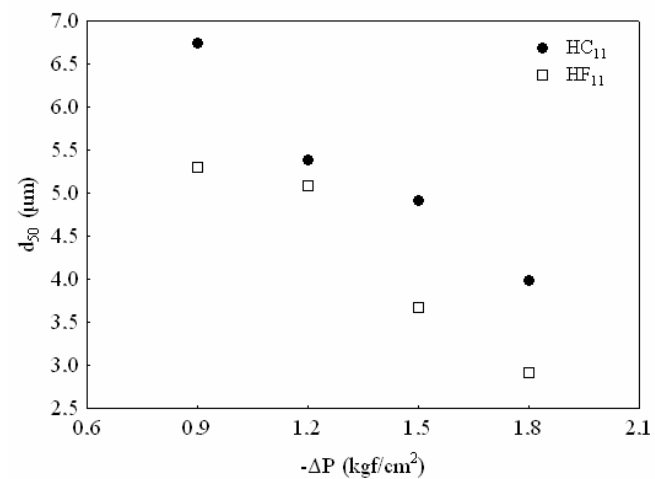

Figure 4: Experimental results of cut size (d50) for conventional and filtering hydrocyclones $\quad(\mathrm{DU}=4$ $\mathrm{mm}$ and $\ell=12 \mathrm{~mm}$ ). this result. Figure 5 shows the simulated profile of radial velocity at $0.04 \mathrm{~m}$ above the underflow orifice, for both hydrocyclones $\left(\mathrm{HF}_{11}\right.$ and $\left.\mathrm{HC}_{11}\right)$ with the same geometry $\left(\mathrm{D}_{\mathrm{U}}=4 \mathrm{~mm}\right.$ e $\left.\ell=12 \mathrm{~mm}\right)$.

In Figure 5, the negative values of the radial velocity indicate the direction: from the wall to the center (axis). The results of this figure show that the radial dragging towards the center is higher for the conventional hydrocyclone. For the filtering hydrocyclone, a particle of a given size would have a higher probability to remain in the limit layer (next to the wall) and then be more easily collected in the underflow stream, resulting therefore in greater total efficiency and smaller cut size diameters.

The experimental data and CFD results of this work showed that the filtering configuration $\left(\mathrm{HF}_{11}\right)$ always presented lower Euler Numbers (lower energetic demands) and lower cut size (higher total efficiency) when compared with the conventional one $\left(\mathrm{HC}_{11}\right)$ of the same geometry.

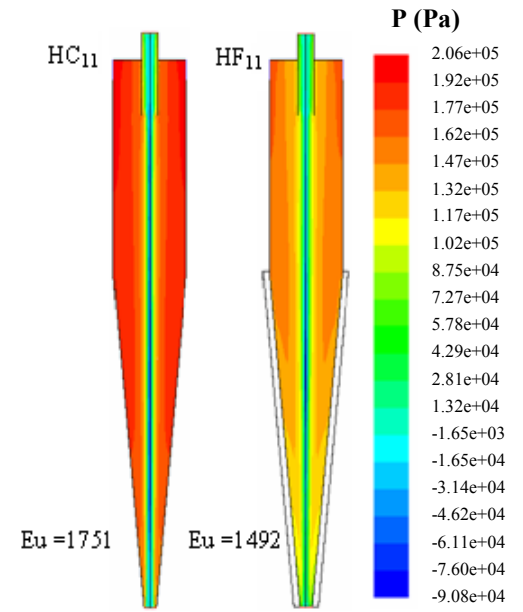

Figure 3: Simulated pressure profiles for conventional and filtering hydrocyclones $(\mathrm{DU}=5 \mathrm{~mm}, \ell=21 \mathrm{~mm}$ and $\mathrm{Q}=301 \mathrm{~cm} 3 / \mathrm{s})$.

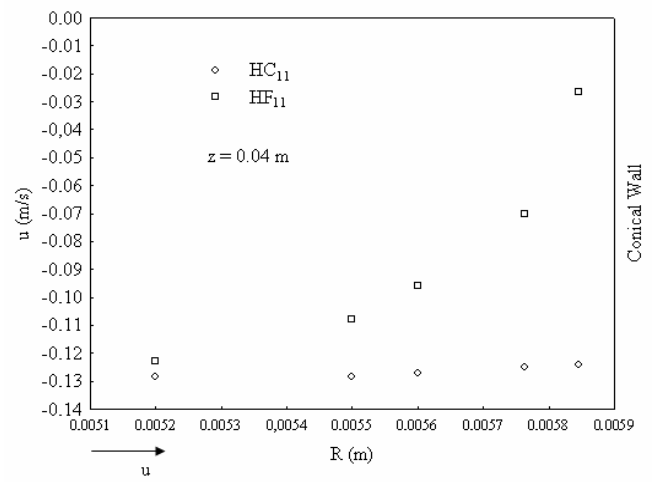

Figure 5: Simulated profiles of radial velocity for conventional and filtering hydrocyclones at $0.04 \mathrm{~m}$ above the underflow orifice (DU $=4 \mathrm{~mm}$ and $\ell=$ $12 \mathrm{~mm})$. 
Influence of the Geometric Variables on the Filtering Hydrocyclone Performance

\section{Influence of the Underflow Orifice Diameter $\left(D_{U}\right)$}

Figure 6 shows the experimental results of Euler Number for the used levels of $D_{\mathrm{U}}$, with $\ell=30 \mathrm{~mm}$. From Figure 6, it can be seen that the Euler Number was higher when smaller underflow orifice diameter was used. This is an expected result, because the lower value of underflow orifice diameter promotes more resistance to the suspension flow in the equipment.

The physical behavior mentioned above is also evidenced by the pressure profile obtained by CFD. Figure 7 shows the CFD results of total pressure profile (relative to an atmospheric pressure value) for filtering hydrocyclones facing the variations of the underflow orifice diameter, at the same inlet flowrate $\left(Q=290 \mathrm{~cm}^{3} / \mathrm{s}\right)$ and with the same vortex finder lengths $(\ell=21 \mathrm{~mm})$. It can be seen in this figure that, when the underflow orifice diameter is decreased, the fluid flow in the device presents a particular distribution of the pressure field, resulting in higher pressure drops (lower Euler Numbers).

It is important to mention that the underflow orifice diameter is directly related to the underflow-tothroughput ratio $\left(\mathrm{R}_{\mathrm{L}}\right)$ and this one, in turn, has a direct influence on the hydrocyclone separation efficiency. Underflow-to-throughput ratios $\left(\mathrm{R}_{\mathrm{L}}\right)$ calculated by CFD techniques are presented in Figure 8, based on the axial velocity profiles, for filtering hydrocyclones with different underflow orifice diameter at the same inlet flowrate $\left(\mathrm{Q}=290 \mathrm{~cm}^{3} / \mathrm{s}\right)$.

The results presented in Figure 8 show that, for the higher value of $\mathrm{D}_{U}(5 \mathrm{~mm})$, the quantity of ascending flow is lower and, consequently, the underflow-to-throughput ratio $\left(\mathrm{R}_{\mathrm{L}}\right)$ is higher. As in the conventional device, this behavior of the

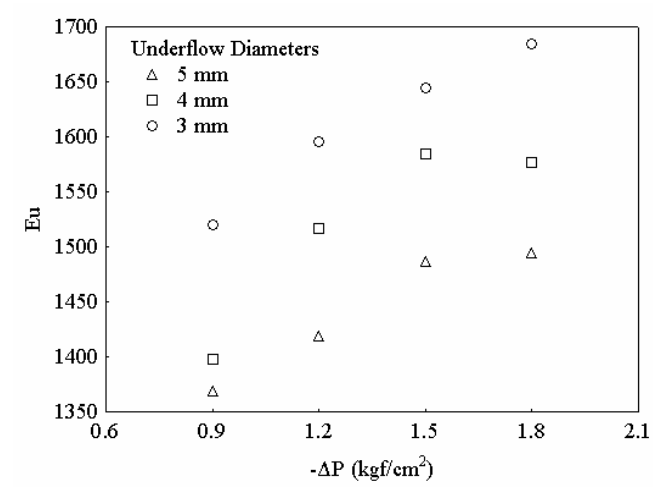

Figure 6: Experimental results of Euler Number for filtering hydrocyclones $\left(\mathrm{HF}_{11}\right)$ with the variations of $\mathrm{D}_{\mathrm{U}}(\ell=30 \mathrm{~mm})$. underflow orifice diameter on $\mathrm{R}_{\mathrm{L}}$ also had a direct influence on the total efficiency of the filtering hydrocyclone, given that the increase in the RL value provides a decrease of the cut size.

The experimental results of cut size for the filtering hydrocyclone with the different $D_{U}$ are presented in Figure 9. The results of Figure 9 confirm the previous analysis done with the results of $\mathrm{R}_{\mathrm{L}}$ by CFD.

\section{Influence of the Vortex Finder Lengths $(\ell)$}

Figure 10 shows the experimental results of Euler Number for the studied levels of vortex finder lengths $(\ell)$, with $\mathrm{D}_{\mathrm{U}}=5 \mathrm{~mm}$. From Figure 10 , it can be seen that, as the vortex finder length $(\ell)$ increases there is an increment in the Euler Number in the filtering hydrocyclone. This means that higher lengths of vortex finder offer a higher resistance to the fluid flow in the equipment. This tendency of the vortex finder effect was also observed in hydrocyclones $\mathrm{HF}_{11}$ assembled with other levels of $\mathrm{D}_{\mathrm{U}}$.

Figure 11 shows the CFD results of axial velocity profile $(\mathrm{w})$ and underflow-to-throughput ratio $\left(\mathrm{R}_{\mathrm{L}}\right)$ for filtering hydrocyclones with different vortex finder lengths $(\ell)$ at the same inlet flowrate $(Q=304$ $\left.\mathrm{cm}^{3} / \mathrm{s}\right)$. These results show that the underflow-tothroughput ratio $\left(\mathrm{R}_{\mathrm{L}}\right)$ is not significantly affected by the vortex finder length $(\ell)$.

The experimental results of cut size for the filtering hydrocyclone $\left(\mathrm{HF}_{11}\right)$ with different vortex finder lengths $(\ell)$ are presented in Figure 12. These results show that, although the vortex finder lengths $(\ell)$ did not have an influence on the underflow-tothroughput ratio (Figure 11), there was a significant influence on the cut size. The filtering hydrocyclone with intermediate level of $\ell(21 \mathrm{~mm})$ presented the higher separation efficiencies (lower cut size).

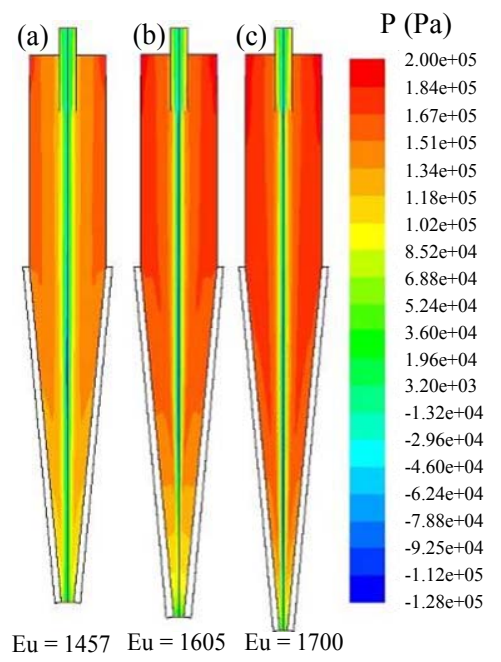

Figure 7: Simulated total pressure profile $(\mathrm{P})$ for filtering hydrocyclones (HF11) with DU of $5 \mathrm{~mm}$ (a), $4 \mathrm{~mm}$ (b), and (c) $3 \mathrm{~mm}$ (with $\ell=21 \mathrm{~mm}$ and $\mathrm{Q}=290$ $\mathrm{cm} 3 / \mathrm{s})$. 


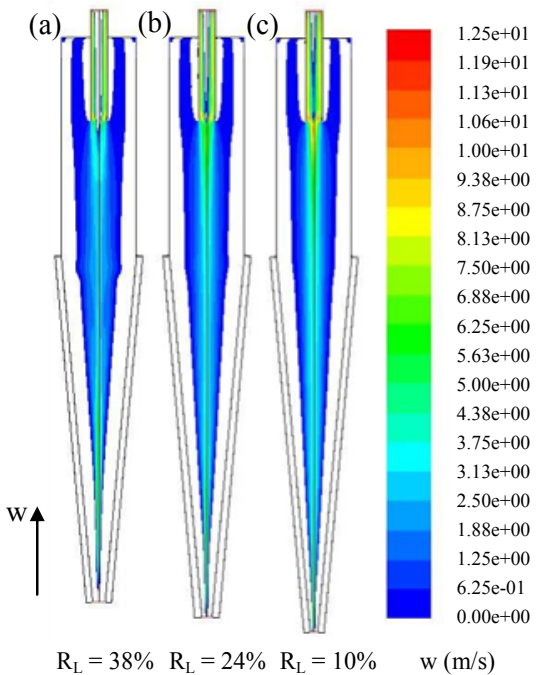

Figure 8: Simulated profiles of axial velocity $(w)$ for filtering hydrocyclones (HF11) with DU of $5 \mathrm{~mm}$ (a), $4 \mathrm{~mm}(\mathrm{~b})$ and (c) $3 \mathrm{~mm}$ (with $\ell=21 \mathrm{~mm}$ and $\mathrm{Q}=290$ $\mathrm{cm} 3 / \mathrm{s}$ ).

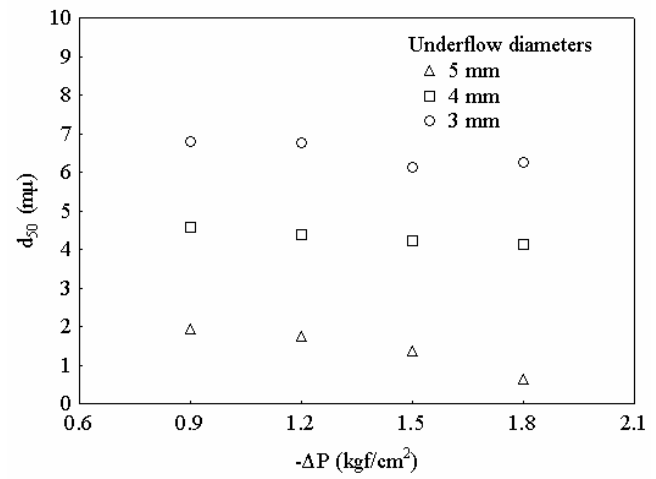

Figure 9: Experimental results of cut size $\left(\mathrm{d}_{50}\right)$ for filtering hydrocyclones $\left(\mathrm{HF}_{11}\right)$ with the variation of $\mathrm{D}_{\mathrm{U}}(\ell=21 \mathrm{~mm})$.

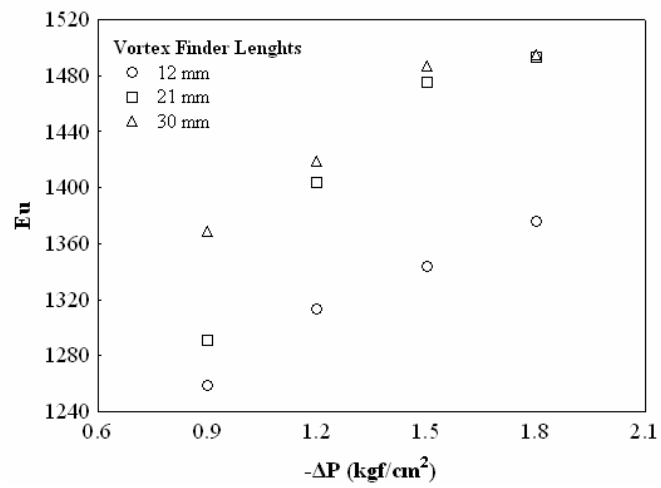

Figure 10: Experimental results of Euler Number for filtering hydrocyclones $\left(\mathrm{HF}_{11}\right)$ with the variations of

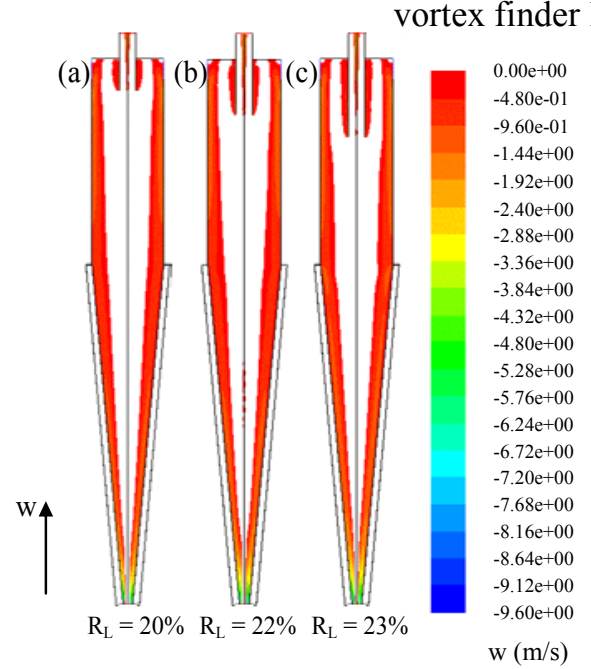

Figure 11: Simulated profiles of axial velocity (w) for filtering hydrocyclones $\left(\mathrm{HF}_{11}\right)$ with $\ell$ of 12 $\mathrm{mm}$ (a), $21 \mathrm{~mm}$ (b) and (c) $30 \mathrm{~mm}$ (with $\mathrm{D}_{\mathrm{U}}=4$ $\mathrm{mm}$ and $\mathrm{Q}=304 \mathrm{~cm}^{3} / \mathrm{s}$ ).

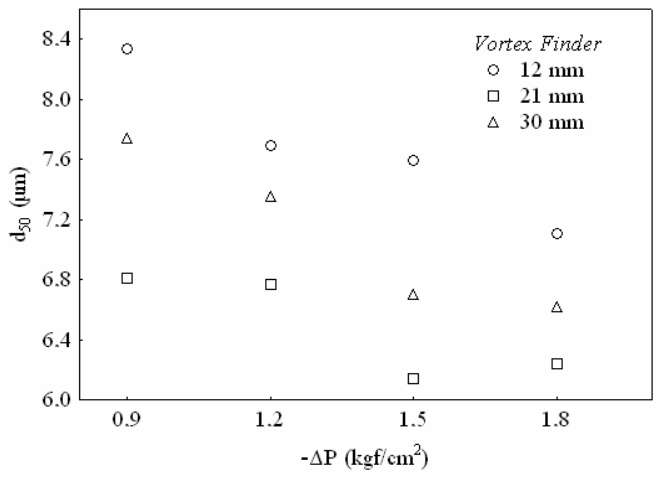

Figure 12: Experimental results of cut size $\left(d_{50}\right)$ for filtering hydrocyclones $\left(\mathrm{HF}_{11}\right)$ with the variation of $\ell\left(D_{U}=3 \mathrm{~mm}\right)$. 
According to Figure 12 results, the cut sizes of filtering hydrocyclone $\left(\mathrm{HF}_{11}\right)$ reach minimum values (maximum efficiencies) when intermediate values of vortex finder are used. Both small and large lengths of vortex finder damage the particle separation in this filtering hydrocyclone. For the smallest level of $\ell$, it is believed that the short circuit phenomenon (between feeding and the overflow diameter) is favored, thus dragging a higher number of particles to the overflow, which contributes to the obtainment of bigger cut size (lower efficiencies). For the highest level of $\ell$, it is believed that this $\ell$ value is also responsible for the collection of a higher number of particles in the overflow, thus leading to high values of cut size. This happens due to the inhibition of migration of particles from the internal to the external vortex (which would return to the underflow stream).

The results of this section showed that the underflow orifice diameter $\left(D_{U}\right)$ and the vortex finder length $(\ell)$ were important variables for the filtering hydrocyclone $\left(\mathrm{HF}_{11}\right)$ performance. The best levels for those variables will depend on the specific functions of the device (classifier or concentrator) according to the interest of each user. If hydrocyclone $\mathrm{HF}_{11}$ is used as a classifier, values of 5 and $21 \mathrm{~mm}$ are indicated for $\mathrm{D}_{U}$ and $\ell$, respectively. If the objective is the concentration of the suspensions, $D_{U}$ and $\ell$ should be 3 and $12 \mathrm{~mm}$, respectively.

\section{CONCLUSIONS}

The results of the present work indicated that the performance of hydrocyclones is significantly influenced by the incorporation of the conical filtering wall. At the same volumetric feed flow rate as that of the conventional hydrocyclone, the filtering hydrocyclone showed a smaller pressure drop. Therefore, the filtering separators presented a lower Euler number and, hence, required less energy to pump the suspension.

The CFD simulations showed that the presence of the filtering wall in the hydrocyclone reduced the radial drag towards the center of the device. Under these conditions, a given particle size was more likely to come to rest close to the porous wall and to be collected in the underflow current. Therefore, the filtering hydrocyclone offers greater total efficiency than the conventional one under the same operational conditions.

Regarding the filtering hydrocyclone $\left(\mathrm{HF}_{11}\right)$, lower Euler Numbers were obtained when the bigger underflow diameter $(5 \mathrm{~mm})$ or the smaller length of vortex finder $(12 \mathrm{~mm})$ were used. In their turn, smaller cut sizes were obtained when a bigger underflow orifice diameter $(5 \mathrm{~mm})$ or an intermediate length of vortex finder $(21 \mathrm{~mm})$ were used.

The best condition for $\mathrm{D}_{\mathrm{U}}$ and $\ell$ will depend on the specific functions of the separator, if it is a classifier or concentrator device. If the need is the classification of particulate material, it is suggested the utilization of hydrocyclone $\mathrm{HF}_{11}$ with $\mathrm{D}_{\mathrm{U}}$ and $\ell$ values of 5 and $21 \mathrm{~mm}$, respectively. In other terms, if the intention is to concentrate suspensions in solids, values of 3 and $12 \mathrm{~mm}$ are the most indicated for $\mathrm{D}_{\mathrm{U}}$ and $\ell$, respectively.

\section{NOMENCLATURE}

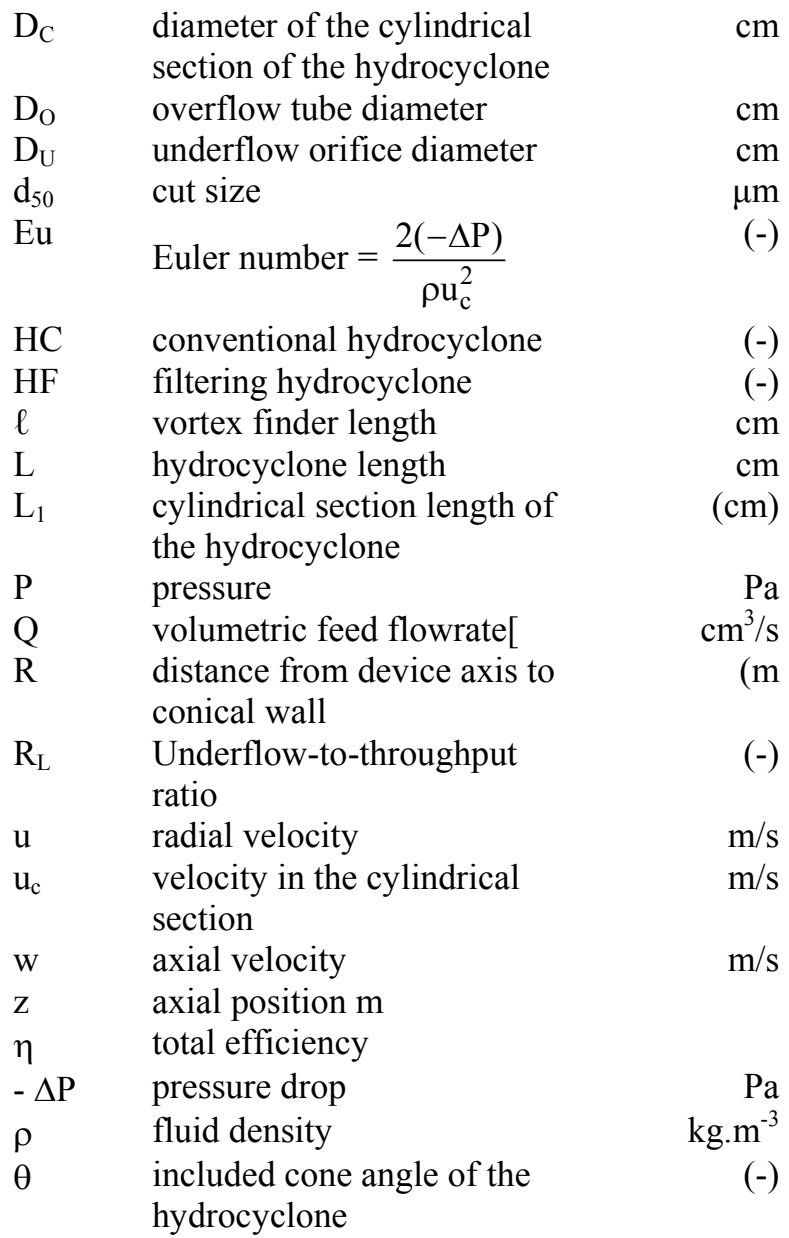

\section{ACKNOWLEDGMENTS}

The authors thank the Brazilian research funding agencies FAPEMIG and $\mathrm{CNPq}$ for their financial support of this work. 


\section{REFERENCES}

Bhaskar, K. U., Murthy, Y. R., Raju, M. R., Tiwari, S., Srivastava, J. K., Ramakrishnan, N., CFD simulation and experimental validation studies on hydrocyclone, Minerals Engineering, 20, 60-71 (2007).

Petty, C. A., Parks, S. M., Flow predictions within hydrocyclones, Filtration and Separation, 28-34 (2001).

Cullivan, J. C., Williams, R. A. Dyakowski, T., Cross, C. R., New understanding of a hydrocyclone flow field and separation mechanism from computational fluid dynamics, Minerals Engineering, 17, 651-660 (2004).

Dai, G. Q., Li, J. M., Chen, W. M., Numerical prediction of the liquid flow within a hydrocyclone, Chemical Engineering Journal, 74, 217-223 (1999).

Fluent 6.3.26, Users Guide, ANSYS, Inc., USA (2008)

Lynch, A. J., Rao, T. C., Modeling and scale-up of hydrocyclone classifiers. In: Carta, M. (Ed.), Proc. 11th Int. Miner. Process. Congr., Cagliari. Aziende Tipografiche Bardi, Rome, 245-269 (1975)

Mainza, A., Narasimha, M., Powell, M. S., Holtham, P. N., Brennan, M., Study of flow behaviour in a three-product cyclone using computational fluid dynamics, Minerals Engineering, 19, 1048-1058 (2006).

Medronho, R. A., Schuetze, J., Deckwer, W., Numerical simulation of hydrocyclones for cell separation, Latin American Applied Research, Bahía Blanca, 35, 1, 1-8, (2005).

Narasimha, M., Sripriya, R., Banerjee, P. K., CFD modelling of hydrocyclone prediction of cut size, Int. J. Miner. Process. 75, 53-68, (2005).

Plitt, I. R., A mathematical model of the hydrocyclone classifier. CIM Bull., 114- 123, (1976).

Schuetz, S., Mayer, G., Bierdel, M., Piesche, M., Investigations on the flow and separation behaviour of hydrocyclones using computational fluid dynamics, Int. J. Miner. Process. 73, 229237, (2004).

Souza, F. J., Vieira, L. G. M. , Damasceno, J. J. R., Barrozo, M. A. S., Analysis of the Influence of the Filtering Medium on the Behaviour of the Filtering Hydrocyclone, Powder Technology, 107, 259-267 (2000)

Svarovsky, L., Hydrocyclone, Holt, Rinehart \& Winston, Eastbourne, UK, 1984.

Vieira, L.G.M., Barbosa, E. A., Damasceno, J. J. R., Barrozo, M. A. S., Performance Analysis and Design of Filtering Hydrocyclones, Brazilian Journal of Chemical Engineering, 22, 143-152 (2005).

Vieira, L. G. M., Otimização dos Processos de Separação em Hidrociclones Filtrantes. Tese de Doutorado, Programa de Pós-Graduação em Engenharia Química, Universidade Federal de Uberlândia (2006).

Vieira, L. G. M., Silva Jr., C. A., Damasceno, J. J. R., Barrozo, M. A. S., A Study of the Fluid Dynamic Behaviour of Filtering Hydrocyclone, Separation and Purification Technology, 58, 282-287 (2007). 